\title{
Linguistics and race: An interdisciplinary approach towards an LSA statement on race
}

\author{
Anne H. Charity Hudley, Christine Mallinson, Mary Bucholtz, Nelson Flores, Nicole \\ Holliday, Elaine Chun, Arthur Spears*
}

\begin{abstract}
In order to work towards greater racial justice within linguistics, the challenge remains for linguists to develop a cohesive theory of and approach to race and racial analysis in linguistics that is influenced by researchers of different methodological approaches and racial backgrounds. A formal LSA statement on race will provide linguistic researchers with a framework for studying race and will also serve as a method of intellectual and social inclusion in linguistics. We draw on interdisciplinary expertise in related fields, including psychology, sociology, anthropology, education, and ethnic studies, to examine how scholars from neighboring disciplines have formally conceptualized and dealt with race and racial classification strategies. Points of convergence as well as divergence are articulated, drawing insights that may advance work related to race within and beyond linguistics.
\end{abstract}

Keywords. linguistics; race; ethnicity; diversity; inclusion; interdisciplinarity

1. Introduction: Why an LSA statement on race? Extensive research in linguistics has made use of the concept of race. Race has been integral to how languages have been defined over time and to how the study of language has developed as a research area. Likewise, language has been central to how race has been theorized and expressed in scholarship, particularly in the Western modern era. Yet, as Charity Hudley (2017) discusses, conflicting models of racial classification have been used in linguistics, and linguists have not developed a cohesive theory or model of race.

Contemporary language study has followed multiple trajectories of investigation and has created competing as well as complementary notions of the role of race in linguistic processes. Research concerning language variation within and across racial and cultural categories has centered on who speaks (or not) a particular language or variety. Linguists still have a tendency to define race with respect to language varieties in particular, as in African-American English or Chicano English. For instance, in large variationist sociolinguistic studies that have characterized the past 50 years of empirical research about language and race, the absence or presence of

\footnotetext{
${ }^{*}$ We gratefully acknowledge the comments and discussion that followed our symposium, "Linguistics and Race: An Interdisciplinary Approach Towards an LSA Statement on Race," at the 2018 LSA Annual Meeting; we also thank colleagues in linguistics and related areas at UCSB, Brown University, and UC-Berkeley, particularly Scott AnderBois and Peter Jenks. The feedback we have received from these and other colleagues has contributed significantly to our thinking and will continue to inform this work and these conversations going forward. Authors: Anne H. Charity Hudley, University of California, Santa Barbara (acharityhudley@ucsb.edu), Christine Mallinson, University of Maryland-Baltimore County (mallinson@umbc.edu), Mary Bucholtz, University of California, Santa Barbara (bucholtz@ucsb.edu) Nelson Flores, University of Pennsylvania (nflores@upenn.edu), Nicole Holliday, Pomona College (Nicole.Holliday@pomona.edu), Elaine Chun, University of South Carolina (chune@mailbox.sc.edu) \& Arthur Spears, City University of New York (aspears@ccny.cuny.edu)
} 
linguistic features is generally correlated with broad definitions of race, but accurate correlation with particular cultural groups in time, place, space, and context has proved more challenging. In contrast, in ethnographic studies, race is defined predominantly by cultural description. Linguists have worked to rely not only on behavioral models of language and race, but also on methods of socialization and the construction of community and culture (Eckert 2012).

Nevertheless, as many have shown, including Hutton (1999) and Baker (2010), while language can be somewhat predictive, predicting culture be a slippery slope that leads into stereotyping. Given the complicated socio-historical history of racial contact and classification, both theoretical and methodological concerns arise in attempts to discern, with a linguistic lens, who is of a particular race and who is speaking what language variety at a given point in time and over time. Linguists and others still struggle with models of racial classification, which tend to capture the tension of racialization - on the one hand, racial classifications and attributions that are prescribed to a person or group, and on the other, racial classifications that individuals and groups ascribe to themselves. Further challenges arise when researchers try to examine and define linguistic systems and cultures that they themselves do not participate in.

A persistent and contributing factor to the lack of formal discussion about race within linguistics, specifically in the U.S., may be the serious underrepresentation of linguistics scholars (including faculty and students) who are of African-American and Latinx descent, as well as those from other traditionally underrepresented groups. In 2015, according to the Linguistic Society of America's annual report, "The population of ethnic minorities with advanced degrees in linguistics is so low in the U.S. that none of the federal agencies report data for these groups" (Linguistic Society of America 2015:16; see also Rickford 2014). Moreover, the leadership within the Linguistic Society of America has also seen serious underrepresentation by linguists of color. Among the small group of linguists of color who are current or past members of the Executive Committee, areas of interest are disproportionately in the realm of syntax and theoretical linguistics, which represents only a small slice of linguistic scholarship.

Compounding these challenges is the fact that the discipline of linguistics has not issued an official statement on race or racial analysis, unlike those put forward by the flagship organizations of the related disciplines of anthropology, sociology, and psychology. For instance, the American Anthropological Association (1999), the American Psychological Association (n.d.a), and the American Sociological Association (2003) all have relatively longstanding formal statements regarding race. They recognize race as a set of beliefs and attitudes about human differences that serves as a basis for the distribution of social privileges and resources, and they acknowledge that prejudice and discrimination are still problems in U.S. society. All of the statements formally outline the historical and social motivations for current racial categories, describe the ways in which academic thought about race in these disciplines originated and has changed over time, and discuss which modes of classification of race and racial work are predominant in these fields. In contrast, the Linguistic Society of America has not issued a formal statement on race and/or racial analysis in linguistics (but see Baugh 1988).

Thus, the challenge remains for linguists to develop a cohesive theory of and approach to race and racial analysis in linguistics that is influenced by researchers of different methodological approaches and racial backgrounds. This paper brings together a diverse group 
of linguists who conduct research that directly involves the topic of language and race: our group represents scholars from a range of racial/ethnic and other intersectional backgrounds, as well as from various subdisciplines and approaches to linguistics. In addition, we draw on our collective interdisciplinary expertise, as each of us has studied and/or conducted scholarship in psychology, sociology, anthropology, education, ethnic studies, or related fields.

In this paper, we examine how scholars from our neighboring disciplines have formally conceptualized and dealt with race and racial classification strategies from a research perspective. We include an analysis of statements and models on race and racial analysis from related disciplines and fields, in order to explore how linguistic research - either uniquely or in combination with these other models - may develop a more comprehensive understanding of and disciplinary approach to race in ways that advance work within and beyond linguistics. Insights drawn from our analysis help address the need within linguistics to develop a formal statement on race; from this work, we aim to lay the groundwork for moving in this direction.

We see this work as crucial for both intellectual and social inclusion within linguistics. A formal statement on race in linguistics can allow for dialogue about what linguistics can uniquely or in combination with other models can contribute to a scholarly understanding of race. Such work may also have a positive influence on other statements and models of research on race, as linguistic work may help uncover some aspects of the dynamic and changing nature of our understanding of race - due to both the finite and discrete, as well as the broad and sweeping ways in which language can be measured, analyzed, and observed. A statement on race in linguistics can also draw diverse students and scholars into the discipline and into academia and help put linguists in conversation with social justice and diversity work in other disciplines and in the academy writ large. Within our own scholarly community, this work can help us think about how linguistics as a discipline is, and should be, engaging with communities and languages spoken by people of different races. It is important, for example, to ensure that linguistic work, whether socially-focused or not, does not have unintentional negative consequences for particular racial groups. This work can help initiate scholarly conversation within linguistic scholarship on such matters and other topics that people of different races are interested in, which would then serve to promote inclusion within linguistics by empowering people from underrepresented groups to ask and engage with questions that are relevant and intellectually curious to them. Finally, many scholars want to know how to be less racist but have not had a chance to engage in anti-racist or inclusion focused education or professional development. A statement on race can also be a starting point and opportunity for that education.

2. Psycholinguistic perspectives on race and racism. The American Psychological Association has a statement, a set of publications, and working documents on race (American Psychological Association n.d.a) as well as an Office of Ethnic Minority Affairs (American Psychological Association n.d.b). These APA materials are designed to inform research as well as internal and external policy and action, as exemplified by the APA's amicus brief on Grutter $v$. Bollinger and Gratz v. Bollinger (2003) and other guidelines, policy statements and resolutions (American Psychological Association n.d.c). The APA has also issued statements on race as a global question (American Psychological Association n.d.d). 
The APA statement on race focuses on the notion that race has a "long and complicated history" and that racism is a persistent issue in the United States (and globally). Psychology has embraced both quantitative and qualitative approaches to the examination of race as psychological identity, the psychological impacts of race on health and wellness, and the sociocognitive impacts of race on education and society (see, e.g., Neville, Tynes \& Utsey 2009; Villaruel et al. 2009). Psychology has advanced our understandings of the educational, social, health, and wellness impacts of racial confidence and ways to mitigate discrimination. These lines of research would be supported by further research in linguistics, building on the findings and work of psychology to examine the impact of such issues as internalized racism and the role that language plays in it, empowerment of racialized groups, and the role of language in the learning processes of racialized students.

Yet the examination of race within psychology has not been without issue. Guthrie (2004) discusses White bias in psychology and the underrepresentation of insights from racial minorities in psychological research. In the name of science, psychological approaches to race have often focused on quantifiable taxonomies such that the classification of race is reduced to a quantitative variable that is put into a program for statistical analysis. This work and others demonstrates a challenge in psycholinguistics where race, widely accepted as a social construct across the social sciences is both within psychology and in some forms of linguistics, made to fit scientific models that reach beyond the realities of race. Within linguistics and psychology, our statistical models of race are still fairly discrete and binary. If race is a social construct, then it is more complicated than simply being used as a discrete variable in a checkbox that is then mostly run as correlation in a statistical model.

Using these methods, racial falsehoods have been claimed, such as continued use of IQ testing, as the development of psychometrics and classification based on intelligence further contributed to systems of racial classification (Lemann 1999). Beliefs about race and IQ still persist, as gross racial classifications continue to be correlated with intelligence scores and academic performance (Herrnstein and Murray 1994) and as seen in work that uses race as a direct correlate to linguistic features, including vocabulary (Hart and Risley 1995). These challenges remind scholars that we must not only focus on quantitative findings but also draw upon actual, scholarly theories of race and interrogate what methods are best used to be racially inclusive in our work.

Future work in this area should integrate social and quantitative examinations of race in ways that aim for social justice. Rather than having a focus on merely counting speakers or linguistic features, we should work towards models that more explicitly aim to empower (not just describe and value) voices. For example, much information for educators about AfricanAmerican English employs a "code-switching" model that is designed to encourage speakers of African-American English to be adept at switching between African-American English and the language variety of the school or dominant culture. Success is measured by acquisition of school knowledge, which encapsulates an ability to "switch" as a latent goal. At their worst, codeswitching models help speakers of African-American English acquire standardized language while demeaning African-American English in the process. At their best, code-switching models help students use their knowledge of African-American English and build on it while helping students acquire standardized English. Either way, the ideology of code-switching, while touted 
as practical and effective in classrooms, is highly racialized. The message that students glean from the hidden curriculum of code-switching is that students and educators are best served by leaving African-American English at the classroom door. The code-switching ideology promotes internalized racism as well as linguistic insecurity for both students and educators. How do we disrupt that model? What are its psychological impacts? Further research on race at the intersections of psychology and linguistics is vital to more fully answering such questions and the implications that they have on speakers from various racial backgrounds.

Psycholinguistics and cognitive science is another major area of research across psychology and linguistics and is arguably more its own field than a subdivision of either linguistics or psychology. From bilingualism research to acquisition of language to examinations of bias, the focus in such research has tended to focus on differences across racial groups and the implications of racism on particular groups, rather than how the models themselves contribute to racialization and racialized modes of analysis as a whole.

More work is therefore needed that explores how research itself relates to racial formation and how researchers themselves view race. In this way, researchers who are interested in language, race, culture, and society are not just examining the impact of race but are also actively creating an intellectually and racially inclusive scholarly community. Tensions surrounding investigations of language and race are intense in large part because scholars who study language and culture have to decide if their primary responsibilities are to a people, racial, or cultural group, or if their responsibilities lie first with the discipline. This is particularly true in psychology, where basic research models can feel removed from communities-particularly communities of color. Our racial models in psychology, linguistics, and psycholinguistics will improve when scholars can more freely intertwine their allegiances to guide their work.

3. Divergence and convergence: Sociology and sociolinguistics. Sociolinguistics has long been narrated as an interdisciplinary field that originated at the intersection of sociology, anthropology, and linguistics (Fishman 1997; Lévi-Strauss 1963; Koerner 2000; Shuy 2003; Paulston and Tucker 2003). In 1963, Claude Lévi-Strauss wrote that the methodological similarity between sociology and linguistics "imposes a special obligation for collaboration upon them" (1963:32). But less than 30 years later, theoretical and methodological connections with sociology had become tenuous. Sociolinguistics began to align more closely with linguistics and anthropology, and language-related areas of sociology (e.g., narrative analysis, the sociology of language) became relatively marginal to sociology as a whole. As such, Fishman (1991:130-32) writes, "only a small proportion of the worldwide sociolinguistic literature is getting through to sociology," while sociolinguists have "created their sociology as they went along," resulting in "self-imposed underexposure to serious sociological stimulation." To solve the problem, Fishman recommends that we "bring the 'socio' back in" to sociolinguistics.

One area to which sociolinguists can look to sociology to "bring the "socio" back in" is in the scholarly treatment of race. As Winant (2000) describes, race has been a significant sociological theme from the founding of the discipline to the present: from the colonialism and biologistic racism inherent in $19^{\text {th }}$ century sociology, to challenges to racism in sociology in the $20^{\text {th }}$ century, to a more critical, global $21^{\text {st }}$ century perspective. Current sociological work on race centers on overcoming prejudice, discrimination, and racism, studying processes of racial 
formation, combating racial injustice, and promoting equality globally and domestically (Winant 2000). Fifteen years ago, the American Sociological Association issued a statement that explores the challenges and contradictions inherent in collecting statistics that allow for comparisons by race. On the one hand, doing so can reify 'race' in ways that promote misconceptions and social divisions; on the other hand, the lack of such measures could obscure inequalities and impede social justice efforts. The statement further points to much significant sociological research on race, including issues of educational inequality, residential segregation, health care, and more. Today, the American Sociological Association has extensive topics and content related to race on its website (n.d.).

As discussed further in Mallinson (2011, 2013), sociological work on race, ethnicity, and stratification is particularly relevant to linguistics in such areas of mutual interest as: linguistic biases that can lead to workplace and housing discrimination for speakers from racial/ethnic minority backgrounds; issues of doctor/patient miscommunication that disproportionately affect racial/ethnic minority groups; the disproportionate racial impact of linguistic policies such as the English Only movement; limited educational opportunities and bias that particularly affect students of color; the study of "racetalk" or racist discourse, and resistance to linguistic inequality and social marginalization by racial/ethnic minority groups. Drawing on sociological literature, as well as on position statements by flagship organizations such as the ASA, can help linguists more fully integrate race as an object of inquiry into sociolinguistic study. Doing so also may be a fruitful avenue for rejuvenating connections between sociology and sociolinguisticsby exploring how language is closely implicated in the construction of racial and ethnic identity, in the dynamics of allegiance and exclusion, and in the perpetuation of durable inequalities in everyday life.

4. The 'race gap': Confronting race and racism in linguistics and anthropology. Despite the close relationship between linguistics and anthropology early in their development in North America (e.g., Hymes 1964; Murray 1998; Paulston \& Tucker 1997), as the disciplines have diverged over the past several decades, a widening gap has also become evident in the understanding of and engagement with race by scholars in each field. Led by anthropologists of color (e.g., Baker 1998; Dominguez 1994; Harrison 1995, 1998; Mukhopadhyay \& Moses 1997), anthropology has been confronting the colonial racist legacy of the discipline and the urgent need to challenge "scientific" racism and other forms of racism both within its own ranks and more broadly (e.g., Brodkin et al. 2011; Shanklin 1998). Although linguists of color have likewise taken the lead in exposing and interrogating historical and contemporary racializing practices within linguistics (e.g., DeGraff 2003, 2004, 2005a, 2005b; Kubota 2002; Leonard 2011; Morgan 1994), the discipline as a whole has been slow to take up the charge issued by this important work. For example, the American Anthropological Association has produced multiple statements related to race and racism and has acknowledged the discipline's role in creating and oppressing racialized groups (e.g., 1994, 1998). To be sure, anthropology has a great deal of work still to do to reimagine its theories and methods from an anticolonial, antiracist perspective, but it offers useful models and inspiration for a similar and long overdue self-examination of our own field.

As a predominantly white discipline rooted in a liberal, Boasian rejection of scientific racism, linguistics struggles to confront its role in reproducing racism. This is largely due to the deeply entrenched societal ideology of racism as intentional and individual rather than structural 
and often below the level of awareness of those who enact it (Bonilla-Silva 2003; Hill 2008; Hodges 2016). Linguists must reject this ideology and overcome white fragility concerning race (DiAngelo 2011) in order to adequately address issues of racism within the discipline. In order to do so, such a task includes the following:

- The need to fully acknowledge the ongoing legacy of the field's history of colonial racism (Errington 2001; Bolton \& Hutton 2000)

- The need for critiques of research that reproduces racialized inequality through claims of racialized groups' linguistic deficits (e.g., the "language gap"; see Avineri et al. 2015)

- The need to undo the practice of racial erasure and racial displacement (Bucholtz 2011) through reliance on untheorized analytic concepts such as "ethnicity" and "culture"

- The need to correct the imbalance between the overresearching of racialized groups and the underresearching of whiteness (Trechter \& Bucholtz 2001)

- The need to understand racialization as a system for reproducing inequality and upholding white supremacy and language as a central tool within that system (Flores \& Rosa 2015; Murji \& Solomos 2005)

For linguists seeking to mentor and support graduate students of color, acknowledging and addressing rather than denying our discipline's role in the reproduction of racism is central to ensuring equity and inclusion in the theory, practice, and teaching of linguistics.

5. Raciolinguistic ideologies and the 'selling' of bilingual education. Raciolinguistic ideologies that co-construct language and race in ways that frame the language practices of racialized communities as inherently deficit play a key role in reproducing white supremacy within our contemporary political and economic context (Flores \& Rosa 2015). Aggarwal (2016) traces these ideologies to the Brown $v$. Board of Education Supreme Court decision and the end of legal segregation in the U.S. In this emergent, post-Brown era of racial formation, the root cause of racial disparities in educational achievement was located not in the inequitable distribution of material resources but rather in the deficiency of racialized students and families. By extension, the solution to racial disparities was framed in terms of changing the individual behaviors of racialized populations rather than structural change to white supremacist institutions. Aggarwal points to invasive interventions intended to close the so-called "word gap" between children from low-income communities of color and mainstream white communities as a contemporary example of this individualistic framing.

This reframing of inequality as an issue of modifying individual behaviors is not unique to the U.S. Instead, it was part of a broader global racial formation that emerged in the post-World War II era, which Melamed (2011) theorizes as a shift from white supremacist modernity to a formally antiracist liberal capitalist modernity. This shift, which deceptively reinforced white supremacy by placing new demands on racialized populations to modify their behaviors, impacted the emerging field of sociolinguistics and the theory of social change that informed the work that came out of it. Indeed, a common view in sociolinguistics is that societies should affirm the language practices of racialized communities while providing them access to dominant ways of using language. While on one level this framing celebrates multiculturalism and multilingualism, on another it is premised on modifying the behaviors of racialized populations in ways that obscure the white supremacy that impacts these populations (Flores \& Rosa 2015). Thus, many interventions proposed by linguists reify the racial formation associated with the latest stage of global capitalism and obscure the nature of white supremacy. This issue is further 
complicated by the lack of an articulated position on race and racism and its relationship to language by organizations such as the American Association for Applied Linguistics.

Bilingual education can be an informative point of entry for understanding contemporary raciolinguistic ideologies. Contemporary support for bilingual education as articulated by proponents of bilingual education is often framed in terms of preparation for participation in a global economic marketplace. Such framing obscures the racial hierarchies that permeate U.S. society and inadvertently aligns bilingualism with the consolidation of white socioeconomic superiority through the valorization of bilingual education among middle- and upper-class whites - which often relies on low-income bilingual and multilingual children of color to function as repositories of cultural difference in service of racially and socioeconomically normative students (Valdés 1997). Thus, particularly in this regard, it is critical for sociolinguistics to more carefully consider how structures of racial privilege and power are reproduced or disrupted through language education programs that we promote.

\section{6. "Check all that apply": Multiracially-identified people and the changing landscape of race and ethnolinguistic variation. While the American Anthropological Association (1999),} the American Sociological Association (2003), and the American Psychological Association (n.d.a) have each issued statements on conceptualizations of race and its importance, these statements have generally overlooked people who identify (or are identified by others) as more than one race. This issue is pervasive across disciplines; even the newly formed Critical Mixed Race Studies Association, an interdisciplinary group focusing on studies of people who identify as more than one race, has (as of the time of this publication) no official statement describing how they conceptualize race or mixed race individuals. Academic awareness and inclusion of people who identify as more than one race has lagged behind rapidly changing demographic patterns in how individuals classify themselves. The 2000 U.S. Census was the first iteration of the massive survey wherein individuals had the ability to check more than one box to identify their race; as a result, scholars of multiracial identity often point to 2000 as a watershed moment for the recognition of multiracial people in the U.S. (Brunsma and Rockquemore 2000). Nearly 20 years later, both academics and federal agencies, including the U.S. Census Bureau, continue to grapple with how to formulate questions about race at a time when population demographics continue to shift, self-categorizations are changing, and individual and group-level identities may be in flux (Cohn 2017).

Like its disciplinary neighbors in sociology, psychology, and anthropology, the field of linguistics has also ignored individuals with more than one racial identity, which has likely obscured some important aspects of variation in linguistic research. For example, though African-American Language is one of the most well-studied varieties of English in sociolinguistics, the majority of studies have either described their participants as monoracial or have neglected to explicitly mention race altogether, rather opting to classify them only by a vague definition of the linguistic variety that they are purported to use (Blake 2014). More recent research, such as Holliday (2016), has specifically begun to study linguistic variation among individuals who identify as having parents of different races, thereby contributing to the expansion of the conversation about the role of participants' self-classifications in sociolinguistic research. In particular, this study found that participant racial alignment is an important predictor of the use of intonational patterns that may be associated with Standard American English or 
African-American Language, with participants who align themselves more with a black identity more likely to use African-American Language prosodic patterns, and individuals who align themselves as more biracial more likely to use Standard American English patterns. As the share of individuals in the U.S. who identify as more than one race or ethnicity continues to increase, linguists and allied scholars will have to be aware of the changing patterns of both externalized and internalized racial identity. Not only is it the ethical responsibility of linguists to accurately reflect speakers' identities in research, but monoracial classifications may also increasingly have the potential to obscure important aspects of identity that influence how we interpret and describe ethnolinguistic variation.

7. Linguistic racialization and Asian American inscrutability. Asian Americans are seemingly inscrutable in studies of language and race. While listeners may sometimes hear the race of Asian Americans (Newman \& Wu 2011), even when no accent is present (Rubin 1992), most scholars of Asian American language have little interest in identifying a variety of English with the structural robustness of other distinctive ethnolectal systems (Lo \& Reyes 2004). At the same time, it cannot be denied that Asian Americans use language to construct their racial identities (Wong \& Hall-Lew 2014, Lo 1999, Reyes 2005), and that Asian Americans are commonly imagined as racialized speakers (Chun 2004). How can we reconcile these facts?

Examinations of Asian American language practices can productively nudge researchers of language and race to reframe their scholarly goals in terms of two related questions: First, how does language become racialized? Second, how do speakers and listeners locate selves and others in relation to racialized language? In other words, by attending to processes of racialization (e.g., Charity Hudley 2017, Chun \& Lo 2015)—namely, the systematic practices and processes that produce (and sometimes contest) our ideologies about language and race-we can come to understand why ethnolectal distinctiveness is not a prerequisite for racialized language practices, why researchers of language of race with seemingly disparate research agendas and methods are in fact engaged in common goals, and how we might transform processes of linguistic racialization in the name of social justice.

8. A statement about linguistics and race: Hmmm.... Preparing a statement about race for any discipline requires some deep and perhaps painful thinking about what the statement should express - and also, crucially, matters that have been under-discussed or omitted in existing disciplinary statements. Highly useful in preparing such a statement on race would be the following intertwined and complex questions. First, who is such a statement for? Are prospective students and researchers envisioned in the audience? If so (and even if not), then we should think about stating succinctly where linguistics has been on the race (class, gender, etc.) front, and where we intend to go. Important also is advancing the discussion, for all disciplines, for example, by recognizing explicitly the essential connection between modern racism and capitalism and also racism and (skin) colorism, both in and outside communities of color. For instance, in their academic work, many students of color choose to write about colorism rather than racism: they have built up some defenses against racism, but colorism and its terms wound deeply as they invade much more the most personal and intimate spaces of students' lives.

Second, how much can actually be said in terms of candor and sociocultural contextualization? Recently, academic work has brought more into focus the differences between 
traditional, say-that-and-we'll-put-you-in-prison censorship and modern (self) censorship, the latter producing a stream of rewards and punishments for airing certain kinds of ideas (see, e.g., many of the writings of Chomsky, as well as Müller 2004, Spears 1999). Can any large organization that solicits funding from mainstream institutions, for example, present an adequate statement on racism, fully informed by a theory of racism in U.S. and global contexts that deals with capitalism, imperialism, exploitation, profit, and ideology (in the critical sense of buttressing vested interests)? Third, how can silences be filled, viz. with respect to social and historical phenomena that are central to but often omitted from discussion of race? Examples include the nature of wealth extraction; the conceptual structure and dissemination of ideology; the actual historical experiences of subordinated groups; key interrelationships among those groups; the relationship among profit, racism, patriarchy, heterosexism, classism, religion phobias, and most of all the function of racism and similar societal ills?

Finally, how could we use the process of producing a statement on race to rethink terminologies and discourses within linguistics? We might ask, for example, how so-called "theoretical linguistics" has come to be privileged in so many linguistics departments, and in what sense applied linguistics and sociolinguistics (to take two examples) are "not" theoretical. Or how we can keep our courses on specific languages (endangered or stigmatized) from being exercises in linguistic tourism, inspecting the languages, as we would ruins of a glorious past, without taking even a moment to consider the lives of the speakers? Considering these questions, and identifying points of convergence as well as divergence from various perspectives, may help advance work in and beyond linguistics - and lay the groundwork within linguistics for developing a formal statement on race.

9. Conclusion: An invitation for response. As we look toward developing a statement on race within linguistics, we invite scholars to reach out to us with their responses to this work and these questions so that this conversation is inclusive and represents perspectives on race from the widest number of scholars possible. We recognize that any such effort is never complete and that our notions of race, and discussion about it, are constantly expanding, changing, and even in dispute. We also recognize that models of race are different across the world (see, e.g., Alim, Rickford \& Ball 2016; DeGraff 2003, 2004, 2005a, 2005b; Mufwene 2001, 2008), and as a result we particularly invite comment from scholars who work on race in communities located outside of the U.S. We invite direct commentary about the following questions in particular:

- Why in 2018, do we need a statement on race? What is race anyway?

- What racial questions are currently allowable in linguistics and which ones should we be asking?

- What existing racial theories is linguistics drawing from?

- Who should be included in the citations in an LSA Statement on Race?

- How are theories of race and previous work on race operationalized in linguistics and linguistic research?

- How might would specific and unique insights from linguistics influence other statements, models, and research on race?

- What can linguistics uniquely or in combination with other models contribute to our understanding of race and how does that intersect with other statements?

- How can people from underrepresented racial groups be empowered in linguistics? How linguistics can be less racist? 
We invite you to contact us directly, and we have also set up a website to receive comments at: https://charityhudleymallinson.com/LSARace. We look forward to continuing the conversation.

\section{References}

Aggarwal, Ujju. 2016. The ideological architecture of whiteness as property in educational policy. Educational Policy (30). 128-52.

Alim, H. Samy, John R. Rickford \& Arnetha F. Ball (Eds.). 2016. Raciolinguistics: How language shapes our ideas about race. New York: Oxford University Press.

American Anthropological Association. 1994. Statement on "race" and intelligence. http://s3.amazonaws.com/rdcmsaaa/files/production/public/FileDownloads/pdfs/cmtes/minority/upload/AAA Statement_o n-_Race_Intelligence1994.pdf

American Anthropological Association. 1999. American Anthropological Association statement on "race." American Anthropologist 100(3). 712-13. http://www.aaanet.org/stmts/racepp.htm.

American Psychological Association. n.d.a. Psychology topics: race. http://www.apa.org/topics/race/index.aspx

American Psychological Association. n.d.b. Office of Ethnic Minority Affairs. http://www.apa.org/pi/oema/index.aspx

American Psychological Association. n.d.c. Guidelines, policy statements and resolutions. http://www.apa.org/pi/oema/resources/policy/index.aspx

American Psychological Association. n.d.d. Justification statement resolution on racism and racial discrimination: A policy statement in support of the goals of the World Conference Against Racism, Racial Discrimination, Xenophobia and Related Intolerance. https://www.apa.org/pi/oema/programs/racism/un-justification.pdf

American Sociological Association. 2003. The importance of collecting data and doing social scientific research on race. Washington, DC: American Sociological Association. http://www2.asanet.org/media/asa_race_statement.pdf

American Sociological Association. n.d. Race and ethnicity. http://www.asanet.org/topics/raceand-ethnicity

Avineri, Netta, et al. 2015. Invited forum: Bridging the "language gap." Journal of Linguistic Anthropology 25(1):66-86.

Baker, Lee D. 1998. From savage to Negro: Anthropology and the construction of race, 18961954. Berkeley: University of California Press.

Baker, Lee D. 2010. Anthropology and the racial politics of culture. Durham: Duke University Press.

Baugh, John. 1988. Language and race: Some implications for linguistic science. In Frederick J. Newmeyer (ed.), Language: The socio-cultural context. Vol. 4 of Linguistics: The Cambridge survey. 64-74.

Blake, Renee. 2014. African American and Black as demographic codes. Language and Linguistics Compass, 8(11). 548-63.

Bolton, Kingsley \& Christopher Hutton (eds.). 2000. Orientalism and linguistics. Special issue of Interventions: International Journal of Postcolonial Studies.

Bonilla-Silva, Eduardo. 2003. Racism without racists: Color-blind racism and the persistence of racial inequality in the United States. New York: Rowman \& Littlefield. 
Brodkin, Karen, Sandra Morgen \& Janis Hutchinson. 2011. Anthropology as white public space? American Anthropologist 113(4). 545-56.

Brunsma, David L. \& Kerry Ann Rockquemore. 2002. What does "Black" mean?: Exploring the epistemological stranglehold of racial categorization. Critical Sociology 28(1-2). 101-21.

Bucholtz, Mary. 2011. White kids: Language, race, and styles of youth identity. New York: Cambridge University Press.

Charity Hudley, Anne H. 2017. Language and racialization. In Ofelia García, Nelson Flores, and Massimiliano Spotti (eds.), The Oxford Handbook of Language and Society. New York: Oxford University Press.

Chun, Elaine. 2004. Ideologies of legitimate mockery: Margaret Cho's revoicings of mock Asian. Pragmatics 14. 263-89.

Chun, Elaine \& Adrienne Lo. 2015. Language and racialization. In Nancy Bonvillain (ed.), The Routledge Handbook of Linguistic Anthropology. 220-32. New York: Routledge.

Cohn, D’Vera. 2017. Seeking better data on Hispanics, Census Bureau may change how it asks about race. Pew Research Center. April 20.

DeGraff, Michel. 2003. Against creole exceptionalism. Discussion note. Language 79. 391-410.

DeGraff, Michel. 2004. Against creole exceptionalism (redux). Language 80. 834-39.

DeGraff, Michel. 2005a. Linguists' most dangerous myth: The fallacy of Creole Exceptionalism. Language in Society 34. 533-91.

DeGraff, Michel. 2005b. Morphology and word order in "creolization" and beyond. In Guglielmo Cinque \& Richard S. Kayne (eds.) Comparative syntax. 293-372. New York: Oxford University Press.

DiAngelo, Robin. 2011. White fragility. International Journal of Critical Pedagogy 3(3). 54-70.

Dominguez, Virginia R. 1994. A taste for "the Other": Intellectual complicity in racializing practices. Current Anthropology 35(4). 333-48.

Eckert, Penelope. 2012. Three waves of variation study: The emergence of meaning in the study of sociolinguistic variation. Annual Review of Anthropology 41. 87-100.

Errington, Joseph. 2001. Colonial linguistics. Annual Review of Anthropology 30. 19-39.

Fishman, Joshua A. 1991. Putting the 'socio' back into the sociolinguistic enterprise. International Journal of the Sociology of Language 92. 127-38.

Fishman, Joshua A. 1997. Bloomington, summer of 1964: The birth of American sociolinguistics. In Christina Paulston \& G. Richard Tucker (eds.), The early days of sociolinguistics: Memories and reflections. 87-95. Dallas: Summer Institute of Linguistics.

Flores, Nelson \& Jonathan Rosa. 2015. Undoing appropriateness: Raciolinguistic ideologies and language diversity in education. Harvard Educational Review 85(2). 149-71.

Grutter v. Bollinger, 539 U.S. 306, and Gratz v. Bollinger, 539 U.S. 244. 2003. http://www.apa.org/about/offices/ogc/amicus/grutter.aspx

Guthrie, Robert V. 2004. Even the rat was white: A historical view of psychology, $2^{\text {nd }}$ edition. Boston, MA: Allyn Bacon.

Harrison, Faye V. 1995. The persistent power of "race" in the cultural and political economy of racism. Annual Review of Anthropology 24. 47-74.

Harrison, Faye V. (ed.). 1998. Special issue: Race and racism. American Anthropologist 100(3).

Hart, Betty \& Todd R. Risley. 1995. Meaningful differences in the everyday experience of young American children. Baltimore, MD: Paul H. Brookes.

Herrnstein, Richard J. \& Charles A. Murray. 1994. The bell curve: Intelligence and class structure in American life. New York: Simon \& Schuster. 
Hill, Jane H. 2008. The everyday language of white racism. Malden, MA: Blackwell.

Hodges, Adam. 2016. Hunting for "racists": Tape fetishism and the intertextual enactment and reproduction of the dominant understanding of racism in U.S. society. Journal of Linguistic Anthropology 26(1). 26-40.

Holliday, Nicole R. 2016. Intonational variation, linguistic style and the Black/Biracial experience. Doctoral dissertation, New York University.

Hutton, Christopher M. 1999. Linguistics and the Third Reich: Mother-tongue fascism, race, and the science of language. New York: Routledge.

Hymes, Dell (ed.). 1964. Language in culture and society: A reader in linguistics and anthropology. New York: Harper \& Row.

Koerner, Konrad. 2000. Toward a historiography of linguistics. Philadelphia: John Benjamins.

Kubota, Ryuko. 2002. The author responds: (Un)raveling racism in a nice field like TESOL. TESOL Quarterly 36(1). 84-92.

Lévi-Strauss, Claude. 1963. Structural anthropology. New York: Basic Books.

Lemann, Nicholas. 1999. The big test. New York: Farrar, Straus and Giroux.

Leonard, Wesley Y. 2011. Challenging "extinction” through modern Miami language practices. American Indian Culture and Research Journal 35(2). 135-60.

Linguistic Society of America. 2015. Annual report: The state of linguistics in higher education. Retrieved April 13, 2016, from https://www.linguisticsociety.org/resource/state-linguisticshigher-education-annual-report

Lo, Adrienne. 1999. Codeswitching, speech community membership, and the construction of ethnic identity. Journal of Sociolinguistics 3(4). 461-79.

Lo, Adrienne \& Angela Reyes. 2008. Language, identity and relationality in Asian Pacific America: An introduction. Beyond Yellow English: Toward a linguistic anthropology of Asian Pacific America. New York: Oxford University Press.

Mallinson, Christine. 2011. Social stratification. In Ruth Wodak, Barbara Johnstone \& Paul Kerswill (eds.), The Sage Handbook of Sociolinguistics. Thousand Oaks, CA: Sage Publications.

Mallinson, Christine. 2013. Sociology and sociolinguistics: Current trends, future partnerships. In Fatos Tarifa (ed. and trans.), The sciences of society: Sociology as an integrative discipline for the study of social life. Tirana, Albania: Albanian Academy of Arts and Sciences/Onufri.

Melamed, Jodi. 2011. Represent and destroy: Rationalizing violence in the new racial capitalism. Minneapolis: University of Minnesota Press.

Morgan, Marcyliena. 1994. The African-American speech community: Reality and sociolinguists. In Marcyliena Morgan (ed.), Language and the social construction of identity in creole situations. 121-48. Los Angeles: UCLA Center for Afro-American Studies.

Mufwene, Salikoko S. 2001. The ecology of language evolution. New York: Cambridge University Press.

Mufwene, Salikoko S. 2008. Race, racialism, and the study of language evolution in America. In Language evolution: Contact, competition, and change. 93-112. London: Continuum Press.

Mukhopadhyay, Carol C. \& Yolanda T. Moses. 1997. Reestablishing "race" in anthropological discourse. American Anthropologist 99(3). 517-33.

Müller, Beate, ed. 204. Censorship and cultural regulation in the Modern Age. Amsterdam: Rodopi. 
Murji, Karim, and John Solomos (eds.). 2005. Racialization: Studies in theory and practice. New York: Oxford University Press.

Murray, Stephen O. 1998. American sociolinguistics: Theorists and theory groups. Philadelphia: John Benjamins.

Neville, Helen, Brendesha Tynes \& Shawn O. Utsey. 2009. Handbook of African American psychology. Thousand Oaks, CA: Sage Publications.

Newman, Michael \& Angela Wu. 2011. “Do you sound Asian when you speak English?”: Racial identification and voice in Chinese and Korean Americans' English. American Speech 86 (2). 152-78.

Paulston, Christina B. \& G. Richard Tucker (eds.). 1997. The early days of sociolinguistics: Memories and reflections. Dallas: Summer Institute of Linguistics.

Paulston, Christina B. \& G. Richard Tucker (eds). 2003. Introduction. In Sociolinguistics: the essential readings. 1-3. Malden, MA: Blackwell.

Reyes, Angela. 2005. Appropriation of African American slang by Asian American youth. Journal of Sociolinguistics 9(4). 509-32.

Rickford, John R. 2014. Increasing the representation of under-represented ethnic minorities in linguistics. Paper presented as part of the symposium, Diversity in linguistics, at the Linguistic Society of America annual meeting. Minneapolis, MN: January.

Rubin, Donald L. 1992. Nonlanguage factors affecting undergraduates' judgments of nonnative English-speaking teaching assistants. Research in Higher Education 33(4). 511-31.

Shanklin, Eugenia. 1998. The profession of the color blind: Sociocultural anthropology and racism in the 21st century. American Anthropologist 100(3). 669-79.

Shuy, R. W. 2003. A brief history of American sociolinguistics 1949-1989. In Christina B. Paulston \& G. Richard Tucker (eds.), Sociolinguistics: The essential readings. 4-16. Malden, MA: Blackwell.

Spears, Arthur K. (ed.). 1999. Race and ideology: Language, symbolism, and popular culture. Detroit: Wayne State University Press.

Trechter, Sara \& Mary Bucholtz. 2001. White noise: Bringing language into whiteness studies. Journal of Linguistic Anthropology 11(1). 3-21.

Valdés, Guadalupe. 1997. Dual language immersion programs: A cautionary note concerning the education of language-minority students. Harvard Educational Review 67. 391-429.

Villaruel, Francisco A., Gustavo Carlo, Josefina M. Grau, Margarita Azmitia, Natasha J. Cabrera \& T. Jaime Chahin (2009). Handbook of U.S. Latino psychology: Developmental and community-based perspectives. Thousand Oaks, CA: Sage Publications.

Winant, Howard. 2000. Race and race theory. Annual Review of Sociology 26(1). 169-85.

Wong, Amy Wing-Mei, and Lauren Hall-Lew. 2014. Regional variability and ethnic identity: Chinese Americans in New York City and San Francisco. Language \& Communication 35. 27-42. 